\title{
DETERMINING CONSUMER'S CHOICE AMONG VARIOUS INSURANCE POLICIES: AN ANALYTICAL HIERARCHICAL PROCESS APPROACH
}

\author{
Emmanuel Olateju Oyatoye* \\ Department of Business Administration, \\ University of Lagos, Nigeria. \\ E-mail: eoyatoye@unilag.edu.ng \\ Rukayat Yetunde Folorunso \\ United Bank for Africa Plc. \\ 1, Taylor Road \\ G-Cappa, Iddo, Lagos. \\ E-mail: olaruqoyah@yahoo.com
}

\begin{abstract}
In recent time, how to spend less money on the most secured insurance policy from the services of various insurance companies motivates modern people to buy a policy. However, making the right choice of policy is always the problem. An insurance policy with which individual can easily achieve their goals of insurance and make financial plans does matter under the shadow of accidents, retirement and disasters at any time. This study determines the best choice amongst various insurance policies for consumers' need using analytical hierarchy process (AHP) method in carrying out contrastive analysis with decision criteria and objective alternatives. Many challenges of this kind associated with making a right choice from multiple choices can be remodeled as multi-criteria decision making (MCDM) in order to evaluate the decision weights which serve as the standard for selecting the right policy. The data employed by this study was obtained from expert from two major insurance firms whom are professional in the field of insurance and from customers that are conversant with various kinds of insurance policies. The AHP provides a scientific approach to the quantification of the relative importance of various decision-influencing criteria. The use of AHP also helped in the simplification of the complex problem as well as enable the insured' to understand their demands so that effective decisions are made.
\end{abstract}

Keywords: Determining, consumers' choice, among, insurance policies, analytic hierarchy process.

\section{Introduction}

The Nigerian insurance industry has evolved over the past years following the announcement of new capitalization requirements for companies operating in the sector. With the conclusion of the consolidation exercise, the number of players dropped from 103 to 51 (Vetiva Capital Management Report, 2007). Activities in the sector have, however, noticeably increased; with enhanced public awareness of the sector and their operations, rapid expansion and strategic business acquisitions, improved visibility and strict supervisory regulation. Government reforms in the insurance industry through the current process of recapitalization and consolidation are to restore confidence of the public in the market and enhance international competitiveness of local operators. So, with the social progress and the demand for life quality, people always expect their lives to be fully secured. An insurance policy with which we can easily achieve our goals of insurance and make financial plans does matter under the shadow of accidents and disasters at any time. Today, how to spend less money on the most secured insurance policy from services of various insurance companies for their dreams motivates modern people to buy a policy. 
Since people's desires never stop and always change, what will best satisfy the desires? Most insurance advisors are consulted orally by their clients and plan the insurances with professionals' perspectives, but how could the insured know for sure that their policies indeed meet their demands? This study aims at how to make the best choice among various insurance policies for our needs while avoiding unprofessional salespersons and exaggerating insurance brokers.

Real-world decision-making problems are usually too complex and ill-structured to be considered through the examination of a single criterion, attribute, or point of view that will lead to the optimum decision. In fact, such a one-dimensional approach is merely an oversimplification of the actual nature of the problem at hand, and it can lead to unrealistic decisions. A more appealing approach would be the simultaneous consideration of all pertinent factors that are related to the problem. However, through this approach some very essential issues/questions emerge: how can several and often conflicting factors be aggregated into a single evaluation model? Is this evaluation model a unique and optimal one? Researchers from a variety of disciplines have tried to address the former question using statistical approaches, artificial intelligence techniques, and operations research methodologies. The success and usefulness of these attempts should be examined with regard to the second question. Obviously, a decision problem is not addressed in the same way by all decision makers. Each decision maker has his or her own preferences, experiences, and decision-making policy; thus one person's judgment is expected to differ from another's. This is a significant issue that should be considered during the development of decision-making models. Addressing such issues constitutes the focal point of interest in multiple-criteria decision making (MCDM).

\subsection{Statement of the problem}

In Nigeria, some earliest and the most resilient problems the insurance industry and the broking firms in particular has been contending with, and will continue to contend with, is the problem of ignorance on the benefits of insurance products. Delay of settlement of genuine claims; low level of regulatory compliance; absence of new products; delayed remittance of premium by intermediaries; inroad of banks into the industry; moral hazards and sharp practices; government's policy inconsistency; weak regulatory measures; illegal commissions and rebates; and poor image of the industry.

Without even taking cognizance of prevalent general insufficiency of income among Nigerians to patronize insurance, what about the well-known conception that a typical Nigerian insurance company is never ready to pay in any event of sad occurrence? When compulsory, many Nigerians now prefer cheaper premium 'to fulfil all righteousness'. Some are of the view that even with the government (the biggest consumer of insurance in the land), incidents of debts remain very high. It is alleged that government officials often prefer to divert funds meant for insurance to other uses. In a nutshell, there is high apathy towards insurance in Nigeria.

In Nigeria, some earliest and the most resilient problems the insurance industry and the broking firms in particular has been contending with, and will continue to contend with, is the problem of ignorance on the benefits of insurance products. Delay of settlement of genuine claims; low level of regulatory compliance; absence of new products; delayed remittance of premium by intermediaries; inroad of banks into the industry; moral hazards and sharp practices; government's policy inconsistency; weak regulatory measures; illegal commissions and rebates; and poor image of the industry. Without even taking cognizance of prevalent general insufficiency of income among Nigerians to patronize insurance, what about the well-known conception that a typical Nigerian insurance company is never ready to pay in any event of sad occurrence? Some are of the view that even with the government (the biggest consumer of insurance in the land), incidents of debts remain very high. It is alleged that government officials often prefer to divert funds meant for insurance to other uses. In a nutshell, there is high apathy towards insurance in Nigeria. People are following the track of buying insurance 
nowadays, but do they really know what is about insurance and what type of insurance is available in the market? There are different types of insurance policies available that investors (insured) are often left wondering as to what purpose they all serve and which of the policies to choose from. Today, how to spend less money on the most secured insurance policy from services of various insurance companies is a very big problem. This is what the study seeks to on veil.

\section{Aim and objectives}

The aim of this study is basically to examine the application of Analytical Hierarchical Process (AHP) method in the making of a meaningful decision by the insurance investors (insured). In order to achieve the above stated aim, the following objectives are set: -

i. To make the best choice among various insurance policies in the market.

ii. To avoid unprofessional sales persons by helping them to fully understand the insured's needs and offer the best service quickly and precisely.

iii. To show that a simple method of AHP, with professionals' and clients (insured) opinions combined, will help clients to carefully look into the content of the policies and make the most suitable decision in order that the expectations of the insurance planning is really met.

\section{Research design/Methodology}

\subsection{Instrument development}

There are many different software that help with the use of AHP process, but they are mostly commercial and quite expensive (e.g. Expert Choice). Therefore, a simple computer application was developed in widely popular Microsoft Excel. It has been a very widely applied spreadsheet for these platforms, especially since version 5 in 1993, and it has almost completely replaced Lotus 1-2-3 as the industry standard for spreadsheets. Excel forms part of Microsoft Office. For this study, Microsoft Excel was used in place of the widely used Expert Choice which is originally meant for AHP. The research questionnaire was designed by using the dichotomous questions based on Saaty's scale of preference-- a form of Likert scale.

\subsection{Population and study sample}

Due to the peculiarity of the AHP technique, a logical procedure for making decision is to make use of primary data (Oyatoye, Okpokpo and Adekoya, 2010). Thus, the data used in the study is the response from expert and insured in an insurance organization (based on their scale of preferences as in the questionnaire distributed). AIICO and Union Assurance insurance companies will be our sample population and the data used for this study is obtained from their branches in Lagos. The choice of Lagos is due to its nature as a metropolitan city where most Nigerian ethnic groups, working class and civil servant were largely represented. For the purpose of this study, the sample size was determined subjectively: 120 questionnaires were administered which was shared equally between the two insurance companies.

\section{Data analysis}

A set of structured questionnaire was distributed to the selected respondents. It was adapted from Saaty's preference scale. The research questionnaire contains 31 questions out of which 10 questions deal with the basic demands for insurance and addressing respondents' need for insurance, while the 
remaining 21 questions deal with the insurance policies in the market. 120 set of questionnaires were administered, 80 of which were administered to the experts (Insurance agents, marketer, senior and junior staff of the insurance company) while the remaining 40 for the clients (the insured). Since experts are trustworthy for their various experiences and deeper knowledge about all kinds of insurance policies than the insured's.

The AHP method was adopted using Microsoft Excel software, which can be downloaded from the internet. The weight for calculation in AHP method is acquired from the questionnaires that have been filled by respondents. The process of analysis by using the AHP method is done in two stages as follows (Taylor III, 2002):

i. First Stage: Determining the best insurance policy, as follows: (a) Establishing the Pair-wise Comparison Matrix for each decision alternative for each criterion, (b) Synthesization, (c) Establishing the Pair-wise Comparison Matrix for each criteria, (d) Establishing the Normalized Matrix, (e) Establishing the Preference Vector (f) Calculating overall values for each decision alternative, and (g) Determining the rank of alternatives according to the values that have been acquired in the previous stage.

ii. Second Stage: Test of Consistency, After analyzing the data by using the AHP method, the result of the selection process must be tested for consistency. The test of consistency is done by using the formula (1), (2), (3) and Table 3.3 (Random Consistency Index). 
Decision alternatives with their corresponding total priority

\begin{tabular}{|l|c|}
\hline Decision Alternative & Total weight (Priority) \\
\hline Serious Illness (SI) & 0.0860 \\
\hline Disability Insurance (DI) & 0.0243 \\
\hline Deposit Health Insurance (DH) & 0.0505 \\
\hline Vehicle Insurance (VI) & 0.1123 \\
\hline Landlord Insurance (LI) & 0.1488 \\
\hline Fidelity Bond Insurance (FB) & 0.0509 \\
\hline Old Age pension (OA) & 0.0850 \\
\hline Annuities Insurance (A) & 0.0674 \\
\hline Investment Style Insurance (IS) & 0.1043 \\
\hline Money Back Policy (MP) & 0.0222 \\
\hline Whole Life Assurance (WL) & 0.0451 \\
\hline Term Assurance (TA) & 0.0250 \\
\hline Child's Deferred Assurance (CD) & 0.1131 \\
\hline School Fees Insurance (SF) & 0.0653 \\
\hline Total priority & 1.0000 \\
\hline
\end{tabular}

\section{REFERENCES}

Oyatoye E.O., Okpokpo G.U. \& Adekoya G.A. (2010). Application of analytic hierarchy process to investment portfolio selection in the banking sector of the Nigerian capital market. Journal of Economics and International Finance, 2(12), 321-335.

Saaty T.L. (1980). The Analytic Hierarchy Process. McGraw-Hill, New York.

Saaty T. L. (1986). Axiomatic foundation of the analytic hierarchy process. Management Science, .32, 841-855.

Saaty T.L. (1994). Fundamentals of Decision Making and Priority Theory with the Analytic Hierarchy Process. RWS Publications, Pittsburgh, PA., pp 38.

Taylor III, B.W. (2002). Management Science $7^{\text {th }}$ ed. New Jersey: Pearson Prentice-Hall, Inc.

Executive Summary (2007). The Nigerian Insurance Sector: Diamonds in the Rough, Issued on Industry Research Report, Vetiva Capital Management. 